\title{
COOPERATIVISMO E TRIBUTAÇÃO: UM ESTUDO DO RAMO AGROPECUÁRIO BRASILEIRO.
}

\section{COOPERAT IVISM AND TAXATION: A ST UDY OF BRAZILIAN AGRICULT URAL BUSINESS}

HUGO DE CASTRO E ANDRADE

E-mail: hugocandrade@yahoo.com.br
MATEUS DE CARVALHO REIS NEVES

E-mail: mateuscrneves@inbox.com

\begin{abstract}
Resumo
As cooperativas, pelo novo Código Civil, são caracterizadas como sociedades simples, sem fins lucrativos. Daí advém implicações hermenêuticas que envolvem diretamente a aplicação do Direito Tributário nessas sociedades. Este artigo visa demonstrar, através da análise do ramo agropecuário do Cooperativismo, como o recolhimento de tributos concerne às organizações que dele fazem parte, mencionando quais destes tributos são passíveis de serem questionados, analisando, para tanto, alguns antecedentes e pareceres de tribunais sobre incidência ou não de tributos em cooperativas. Para isso, explora peculiaridades do Cooperativismo e alguns conceitos teóricos de Direito Tributário. Outrossim, o estudo de uma cooperativa específica se propõe a demonstrar o real impacto dos tributos sobre uma cooperativa agropecuária de médio porte, através de análise financeira e levantamento dos impostos recolhidos pela cooperativa. Os resultados evidenciam que, apesar de pertencer ao ramo cooperativo com menor carga tributária, ainda assim as cooperativas possuem tributação significativa, indicando que a incidência final pode ser outra, que não aquela acenada pelo Estado, com suas políticas de fomento ao setor.
\end{abstract}

Palavras-chave: Cooperativas Agropecuárias, Direito Tributário, Tributação em Cooperativas.

\begin{abstract}
The cooperatives, according to the Civil Code, are characterized as simple society, without lucrative objectives. From this broad conception, hermeneutic implications may be considered due to the application of the Tax Law in this type of society. This article intends to demonstrate, through the analysis of the farming branch of the Cooperatives, that the collection of tributes may be questioned, especially when some jurisprudence on incidence or not of tributes in cooperatives are analyzed. In such way, it explores peculiarities of the Cooperatives and some theoretical concepts that come from Tributary Law. Also, the study of a specific cooperative have the objective to demonstrate the real impact of the tributes on middle-size farming cooperative, through financial analysis and survey of the taxes collected for the cooperative are overstated. The results show that, although to belong to the cooperative branch with lesser tax burden, it still has a significant taxation, indicating that the Government policies to the sector needs to be reviewed.
\end{abstract}

Key-words: Agriculture Cooperatives, Tributary Legislation, Cooperative Tributes. 


\section{INTRODUÇÃO}

O cooperativismo, tal como o conhecemos hoj e, tem sua origem na experiência dos Pioneiros de Rochdale (Inglaterra, 1844). Esse fato histórico é reconhecido como o marco do cooperativismo em todo o mundo, apesar de haver, em períodos anteriores a este, formas de organização e solidariedade entre os homens que se assemelhassem aos objetivos das incipientes cooperativas, a saber: necessidade dos homens de unir-se para solucionar problemas que Ihes eram comuns.

Depois do resultado positivo desse trabalho pioneiro, diferentes trabalhadores das mais variadas classes passaram a associar-se em cooperativas na busca de solução para problemas econômicos e sociais que Ihes afligiam.

Utilizaremos como conceito de cooperativa o mesmo empregado por Renato Lopes Becho, com o brilhantismo que Ihe é peculiar. Para ele, "as cooperativas são sociedades de pessoas, de cunho econômico, sem fins lucrativos, criadas para prestar serviços aos sócios de acordo com princípios jurídicos próprios e mantendo seus traços distintivos intactos" (BECHO, 2005, p. 95).

Sociedades de pessoas porque, conforme expõe Becho, o capital perde em importância para os membros individualizados que buscam uma alternativa para remunerar seu trabalho, não seus recursos econômicos.

"O cunho econômico destaca que as cooperativas não são sociedades beneficentes ou culturais. Os sócios visam incrementos econômicos para si, o que tem causado muita confusão para os desconhecedores da matéria, já que confundem conteúdo econômico com lucro. Não é o caso." (BECHO, 2005, p. 96)

Sem fins lucrativos porque "a cooperativa não existe para criar riqueza e depois distribuí-la na proporção de sua participação societária" (BECHO, 2005, p 96), mas sim para, conforme salientado acima, incrementar economicamente os sócios, em seus contatos com a sociedade e com o mercado.

Quanto à prestação de serviços,

é esta a realidade da atividade cooperativista, independentemente do objeto da atuação sociedade. Mesmo uma cooperativa de produção, com caráter industrial, adéqua à afirmação. (...) Explica-se: a cooperativa sempre será um meio para uma melhoria da situação pessoal do associado, que se beneficiará imediatamente em suas atividades que motivaram sua participação na entidade. O cooperado visa, com a sociedade, diminuir seus custos ou obter melhores preços para os seus produtos ou receber empréstimos a juros melhores etc. A lei de regência dessas sociedades reconhece esta particularidade. (BECHO, 2005, P. 96)

Os princípios jurídicos próprios que regem as cooperativas são adesão livre e voluntária, controle democrático dos sócios, participação econômica dos sócios, autonomia, promoção da educação, prática da intercooperação e preocupação com a comunidade.

A sociedade deve manter traços distintivos intactos porque aquelas que "se mascaram como cooperativas atraiçoam as normas de regência, (...) passa a ser uma falsa cooperativa, praticando o injusto, o injurídico, o ilegal. (...) Crescem como ervas daninhas, empobrecem o jardim e devem ser combatidas como pragas." (BECHO, 2005, p. 96) 


\section{REFERENCIAL TEÓRICO}

\subsection{Cooperativas - Histórico, Definição e a Natureza J urídica}

Vistas sob o prisma da Constituição Federal de 1988, as cooperativas são uma forma societária especial, "com princípios específicos, merecedores de incentivo e de um adequado tratamento tributário, na esteira de relevantes precedentes internacionais." (ANDRIGHI, 2003, p. 50)

No artigo 3ㅇda Lei no 5.764/71, previsto está que "celebram contratos de sociedade cooperativa as pessoas que reciprocamente se obrigam a contribuir com bens ou serviços para o exercício de uma atividade econômica, de proveito comum, sem objetivo de lucro".

É importante salientar que não há dúvidas que uma cooperativa se trata de sociedade e não de associação, visto que esta não admite fins econômicos (artigo 53 do Código Civil).

No artigo 982, parágrafo único, do novo Código Civil, está disposto que a cooperativa será considerada sempre sociedade simples, isto é, não empresária, independentemente do seu objeto. Deste modo, as cooperativas não estão sujeitas à falência, a teor do que dispõe o artigo 94 da Lei de Falências (Lei no 11.101/2005) e o artigo 4 을 Lei $\mathrm{n} 05.764 / 71{ }^{1}$

Não obstante sua natureza não-empresária, os atos constitutivos e demais documentos societários estão suj eitos a registro nas juntas comerciais. ${ }^{2}$

O Código Civil (artigo 1.094) enumera oito características a serem observadas pelas sociedades cooperativas. "Sem embargo, continuam aplicáveis outras características estabelecidas na Lei no 5.764/71, especialmente em seu artigo 40. Além dessas oito características, o Código Civil determina também que a sociedade cooperativa deverá ter o termo 'cooperativa' em sua denominação social (BRAGA, 2006, p. 25).

Consta no artigo 1.094 da Constituição Federal que:

São características da sociedade cooperativa:

I - variabilidade, ou dispensa do capital social;

II - concurso de sócios em número mínimo necessário a compor a administração da sociedade, sem limitação de número máximo;

\footnotetext{
${ }^{1}$ Art. 4으 - As cooperativas são sociedades de pessoas, com forma e natureza jurídica próprias, de natureza civil, não suj eitas à falência, constituídas para prestar serviços aos associados, distinguindo-se das demais sociedades pelas seguintes características:

I - adesão voluntária, com número ilimitado de associados, salvo impossibilidade técnica de prestação de serviços;

II - variabilidade do capital social representado por quotas-partes;

III - limitação do número de quotas-partes do capital para cada associado, facultado, porém, o estabelecimento de critérios de proporcionalidade, se assim for mais adequado para o cumprimento dos objetivos sociais; IV - incessibilidade das quotas-partes do capital a terceiros, estranhos à sociedade;

V - singularidade de voto, podendo as cooperativas centrais, federações e confederações de cooperativas, com exceção das que exerçam atividade de crédito, optar pelo critério da proporcionalidade; $\mathrm{VI}$ - quorum para o funcionamento e deliberação da Assembléia Geral baseado no número de associados e não no capital;

VII - retorno das sobras líquidas do exercício, proporcionalmente às operações realizadas pelo associado, salvo deliberação em contrário da Assembléia Geral;

VIII - indivisibilidade dos fundos de Reserva e de Assistência Técnica Educacional e Social; IX - neutralidade política e indiscriminação religiosa, racial e social;

$X$ - prestação de assistência aos associados, e, quando previsto nos estatutos, aos empregados da cooperativa; XI - área de admissão de associados limitada às possibilidades de reunião, controle, operações e prestação de serviços.

${ }^{2}$ Lei no 5.764/71, artigo 18, $\S 60$ - Arquivados os documentos na Junta Comercial e feita a respectiva publicação, a cooperativa adquire personalidade jurídica, tornando-se apta a funcionar.
} 
Para Braga (2006, p. 21),

III - limitação do valor da soma de quotas do capital social que cada sócio poderá tomar;

IV - intransferibilidade das quotas do capital a terceiros estranhos à sociedade, ainda que por herança;

$\mathrm{V}$ - quorum, para a assembléia geral funcionar e deliberar, fundado no número de sócios presentes à reunião, e não no capital social representado;

VI - direito de cada sócio a um só voto nas deliberações, tenha ou não capital a sociedade, e qualquer que seja o valor de sua participação;

VII - distribuição dos resultados, proporcionalmente ao valor das operações efetuadas pelo sócio com a sociedade, podendo ser atribuído juro fixo ao capital realizado;

VIII - indivisibilidade do fundo de reserva entre os sócios, ainda que em caso de dissolução da sociedade.

é visível [...] a singularidade e o hibridismo das cooperativas: são sociedades (pois exercem atividade econômica), mas não têm intuito de lucro; são não-empresárias, mas registram-se nas juntas comerciais; aproximam-se, por sua história, seu objeto e sua finalidade, do Direito Societário e do Direito do Trabalho.

Os dispostos acima, aliados à existência de normas e princípios próprios, levam-nos à conclusão de que é possível falar-se num novo ramo do Direito, o Cooperativo, uma vez que as cooperativas não se enquadram em nenhum dos ramos tradicionais (Direito Civil, Direito Comercial, Direito Administrativo, Direito do Trabalho, etc.).

Como bem leciona Renato Lopes Becho (2002, p.50),

entendemos que não é mais possível classificar-se as pessoas jurídicas apenas como sociedades ou associações civis, fundações e sociedades ou associações comerciais. Há que se reconhecer a existência de uma terceira espécie ao lado das civis e comerciais, que é a cooperativa.

\subsection{Ato Cooperativo}

De acordo com a Lei no 5.764/71, em seu artigo 79, "denominam-se atos cooperativos os praticados entre as cooperativas e seus associados, entre estes e aquelas e pelas cooperativas entre si quando associadas, para a consecução dos objetivos sociais." Disposto está, também, que 0 ato cooperativo não implica operação de mercado, contrato de compra e venda de produto ou mercadoria.

Com base nisso, muitos doutrinadores e, principalmente, o Fisco entendem que os atos praticados pela cooperativa que envolva terceiros não se caracterizam como verdadeiros atos cooperativos. Assim, a venda de mercadorias ou serviços, independentemente se praticados pelos cooperados, por envolverem terceiro não cooperado na outra ponta, não se enquadraria no conceito de ato cooperativo, segundo esse entendimento. Entretanto, essa interpretação é demasiadamente restritiva, e torna o tratamento dado ao ato cooperativo inócuo, já que dificilmente uma cooperativa sobrevive sem manter relações com terceiros, seja para adquirir, seja para fornecer mercadorias ou serviços.

Por tal motivo, uma segunda corrente doutrinária aduz que o conceito de ato cooperativo não pode ser interpretado literalmente, mas deve levar em conta tal realidade; daí porque assume que, tratando-se de ato em que exista um cooperado na ponta da relação, deve este ser considerado, sim, ato cooperativo e, portando, suj eito a tratamento diferenciado dos demais. Assim, a compra e/ ou venda de produtos e serviços a terceiros sempre será ato cooperativo desde que a compra e/ ou venda do produto ou serviço seja praticada pelo cooperado, com vistas ao cumprimento dos objetivos sociais da 
cooperativa. Esse entendimento é aquele que se sustenta perante os juízes e tribunais. E tal entendimento é ostensivamente combatido pelo Fisco.

$\mathrm{Na}$ cooperativa, o associado atua como proprietário e como beneficiário, e uma relação ocorre como resultado de outra. "É condição sine qua non, na cooperativa, ser proprietário para ser consumidor, apesar de que, por forças das circunstâncias, principalmente pelo mercado, pode a cooperativa operar com não-sócios" (BECHO, 2005, p. 164).

\subsection{Tributos}

Tributo é a participação imperativa do indivíduo, da empresa e da instituição no sentido de angariar fundos para cobrir os dispêndios da entidade tributante visando à conservação e a consecução de serviços públicos. Essa obrigação tributária é o exercício de poder jurídico

por força do qual uma pessoa (suj eito ativo) pode exigir de outra (sujeito passivo) uma prestação positiva ou negativa (objeto da obrigação) em virtude de uma circunstância reconhecida pelo direito como produzindo aquele efeito (causa da obrigação). (SOUSA, 1975)

A Constituição Federal, em seu art. 153, definiu os seguintes impostos sob a competência tributária da União:

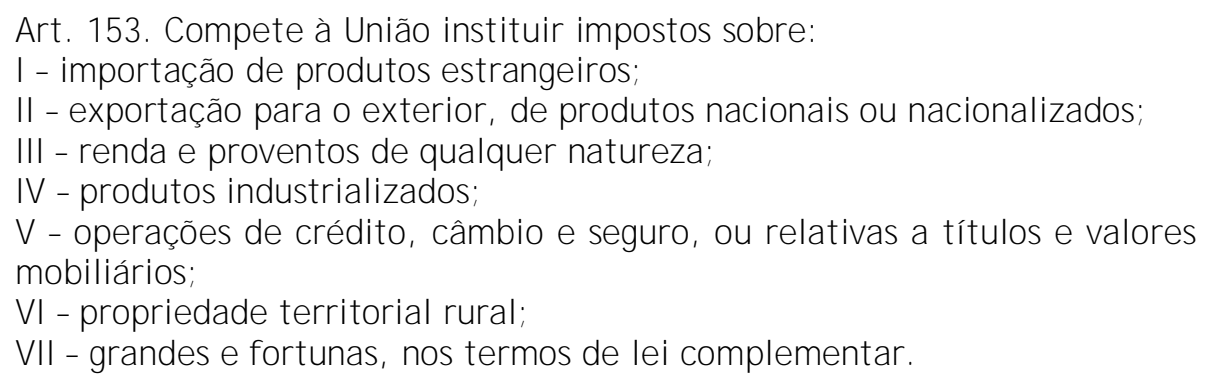

No presente artigo, nos ateremos ao inciso III, mais especificamente a respeito do Imposto sobre a Renda e Proventos de Qualquer Natureza. A seleção deste tributo se deu pela reiterada aparição em tribunais acerca de sua incidência ou não sobre atos cooperativos.

Também vamos discorrer mais detidamente a respeito do ICMS, pois, assim como o Imposto de Renda, trata-se de um imposto com grande repercussão jurídica em âmbito nacional.

O Imposto Sobre Circulação de Mercadorias e Serviços vem previsto no art. 155 da Constituição Federal, como sendo um tributo de competência dos Estados e do Distrito Federal:

Art. 155. Compete aos Estados e ao Distrito Federal instituir impostos sobre: $(\ldots)$

II - operações relativas à circulação de mercadorias e sobre prestação de serviços de transporte interestadual e intermunicipal e de comunicação, ainda que as operações e as prestações se iniciem no exterior.

Percebe-se, pela leitura do art.155, que a sigla ICMS abarca pelo menos 5 impostos diferentes, se levarmos em consideração que cada um deles possui base de cálculo e hipótese de incidência diferentes. São eles, segundo Roque Carrazza (1995, p. 22):

a) o imposto sobre operações mercantis (operações relativas à circulação de mercadorias); b) o imposto sobre serviços de transporte interestadual e intermunicipal; c) o imposto sobre serviços de comunicação; d) o imposto sobre produção, importação, circulação, distribuição ou consumo de 
lubrificantes e combustíveis líquidos e gasosos e de energia elétrica; e, e) o imposto sobre extração, circulação, distribuição ou consumo de minerais.

Deteremo-nos aqui ao citado na letra "a", apontado por Carrazza, por se tratar mais especificamente do que se propõe nosso estudo.

\subsubsection{Sociedades Cooperativas e o Sistema Tributário}

Inúmeras discussões apresentam-se acerca do regime tributário das cooperativas. Alguns defendem haver imunidade tributária, em face do artigo 146, III, "C", da Constituição Federal. $^{3}$ Outros afirmam haver isenção concedida pela legislação de cada imposto, e outros ainda afirmam haver não incidência, diante das peculiaridades do ato cooperativo.

Veja-se em que consiste cada um desses institutos jurídicos: a imunidade, a isenção e a não incidência levam à mesma conseqüência prática - 0 não pagamento do tributo; embora exista significativa diferença no regime jurídico de cada um. As hipóteses de não incidência, portanto, independem de expressa previsão legal. Decorrem da própria hipótese de incidência da lei de tributação. O que nela não couber, é hipótese de não incidência, ou seja, o fato gerador previsto na lei não ocorreu no mundo realístico.

Entre estudiosos e analistas de tributação às sociedades cooperativas, a questão que se faz relevante é a seguinte: o que seria o adequado tratamento tributário ao ato cooperativo?

Adequado não é imune. "Quando o constituinte quis conceder imunidade a alguém ou a algum bem (como aos templos de qualquer culto), ele o fez expressamente, insculpindo a imunização à tributação notadamente no art. 150" (BECHO, 2005, p. 216).

Adequado também não é veículo de isenção tributária.

Devemos entender adequado como compatível, de acordo, aj ustado. "Pode ser: ajustado às suas características peculiares, compatível com sua finalidade social, de acordo com a natureza dos negócios praticados" (BECHO, 2005, p. 216). Ele acrescenta que

É importante destacar que a busca para o adequado tratamento tributário em exame é uma tarefa complexa. Por adequado teremos, em certas circunstâncias (materialidades), a verificação da incidência e para outras circunstancias poderá ser de não-incidência. Em alguma regra-matriz hipotética, um tipo de cooperativa poderá ser contribuinte e, na mesma regra-matriz hipotética, outra cooperativa poderá não ser contribuinte (BECHO, 2005, p. 216).

A Constituição de 1988 não concedeu imunidade ao ato cooperativo, mas tratou de tratá-lo favoravelmente. Além disso, procurou beneficiar o cooperativismo.

A lei complementar que veiculará o tratamento tributário ao ato cooperativo terá, além de uma função declaratória, uma função constitutiva de uma tributação que estimule o cooperativismo, que cumpra em sua inteireza os mandamentos constitucionais, lidos em conjunto e não isoladamente (BECHO, 2005, 218).

O que cabe perguntar é quando tal lei complementar será veiculada. À míngua de uma lei complementar, com ampla dimensão normativa, material e formalmente concebida para cumprir o preceito constitucional, com vistas a estabelecer normas gerais sobre 0 adequado tratamento tributário ao ato cooperativo, surgem, em nosso ordenamento jurídico, diversas medidas provisórias e conseqüentes leis de conversão,

\footnotetext{
${ }^{3}$ Art. 146. - Cabe à lei complementar:

(...)

III - Estabelecer normas gerais em matéria de legislação tributária, especialmente sobre:

(...)

c) Adequado tratamento tributário ao ato cooperativo praticado pelas sociedades cooperativas.
} 
flagrantemente inconstitucionais, por aumentarem, abusivamente, a incidência de tributos sobre os atos das sociedades cooperativas.

\subsubsection{Cooperativismo, Tributação e Incentivos}

Esta seção traz alguns exemplos da abordagem dada à Tributação, mais especificamente àquela inerente às cooperativas agropecuárias. Primeiramente, será feita uma breve análise acerca do cooperativismo agropecuário no Brasil. Em seguida será analisada a Jurisprudência vinculada a alguns dos principais tributos que incidem sobre esse ramo cooperativo, versando sobre IR e ICMS. Posteriormente, a análise da incidência de tributos sobre uma cooperativa agropecuária do Estado do Rio de J aneiro exemplificará o quanto uma típica cooperativa do interior do Estado paga em impostos. Por fim, ainda em referência ao Estado do Rio de J aneiro, daremos dois exemplos recentes de políticas de fomento desempenhadas pelo Governo do Estado: o primeiro referente ao setor pecuário de leite como um todo, afetando também as cooperativas e o segundo concernente diretamente a Cooperativa Central dos Produtores de Leite do Estado do Rio de Janeiro CCPL-RJ .

\subsubsection{Cooperativismo Agropecuário no Brasil}

As cooperativas de produção agrícola vêm apresentando, nas últimas décadas, uma evolução dinâmica e permanente. Elas desempenham importante papel no desenvolvimento econômico e social de seus associados, além de serem organizações que permitem a inserção de pequenos e médios produtores em mercados agropecuários.

0 crescimento populacional e o respectivo aumento na demanda por alimentos foram acompanhados por transformações diversas na agricultura, tais como o rápido desenvolvimento tecnológico e a abertura de novas fronteiras agrícolas. E as cooperativas agropecuárias, inseridas nesse contexto, passaram focar os seus objetivos não apenas na produção de alimentos, mas também na industrialização, armazenamento e comercialização dessa produção, além de prestar assistência (técnica, social e educacional) aos seus cooperados.

No ano de 2007, o Produto Interno Bruto (PIB) agropecuário foi próximo a R\$ 570 bilhões, segundo dados da Confederação Nacional da Agricultura e Pecuária do Brasil (CNA). Desse total, as cooperativas agropecuárias movimentaram cerca de $40 \%$

Segundo Edivaldo Del Grande, atual presidente da Ocesp (Organização das Cooperativas do Estado de São Paulo), é a cooperativa "a principal forma de organização do homem do campo, quando não é única. (...) O grande diferencial vem da organização de pessoas em torno de um objetivo comum, sem visar a concentração de riquezas. (...) A cooperativa aj uda a introduzir tecnologia nas propriedades e aumenta a produtividade".

\subsubsection{J urisprudência}

Aqui buscaremos trazer alguns pareceres de tribunais com relação ao Direito Tributário, de forma especial, em sua relação com o Direito Cooperativo. Tal coletânea reflete não somente as vitórias obtidas nos últimos anos, mas também visa denunciar o quão superficiais são algumas análises feitas pelos tribunais no que tange ao ato cooperativo e à tributação das cooperativas. 


\subsubsection{Imposto de Renda}

Dentre os tributos que aqui nos ateremos, encetamos pelo Imposto de Renda, já destacando 0 art.29 do Decreto 85.450 de 04.12.1980, no qual o Poder Executivo, balizando-se pelos arts. 85,86 e 88 da Lei $5.764 / 71$, mostra-se cônscio de que não tem competência para julgamentos nessa esfera. Tal Decreto foi posteriormente modificado pelo art. 183 do Decreto 3.000/99, ficando assim:

Art. 183. As sociedades cooperativas que obedecerem ao disposto na legislação específica pagarão o imposto calculado sobre os resultados positivos das operações e atividades estranhas à sua finalidade, tais como (Lei 5.764, de 1971, arts. 85, 86, 88 e 111, e Lei 9.430, de 1996, arts. 1o e 20):

1 - de comercialização ou industrialização, pelas cooperativas agropecuárias ou de pesca, de produtos adquiridos de não associados, agricultores, pecuaristas ou pescadores, para completar lotes destinados ao cumprimento de contratos ou para suprir capacidade ociosa de suas instalações industriais;

II - de fornecimento de bens ou serviços a não associados, para atender aos objetivos sociais;

III - de participação em sociedades não cooperativas, públicas ou privadas, para atendimento de objetivos acessórios ou complementares.

E nesse sentido tem sido decidido pelos tribunais, como demonstra o próprio Superior Tribunal de Justiça:

Tributário. Imposto de renda. Cooperativa. Aplicações financeiras.

Se, entre duas interpretações, o regulamento do imposto de renda, baixado por decreto, adota aquela que favorece o contribuinte, o Fisco não pode desconsiderá-la, exigindo o tributo à base da outra; tudo porque a interpretação da lei, pelo Chefe do Poder Executivo, vincula os órgãos hierarquicamente subordinados, e, quando ela é manifestada por decreto, sobrepõe-se, também, formalmente às demais manifestações da Administração. Hipótese em que, muito embora a Lei 5.764, de 1971, também autorize 0 entendimento de que 0 resultado das aplicações financeiras feitas por cooperativas está sujeito ao imposto de renda, o Decreto 85. 450, de 1980, que a regulamentou, e que tem caráter de norma complementar (CNT, art. 100, inc. I), fez por excluí-lo do campo de incidência do tributo. Recurso especial conhecido e improvido (ST), 1998a).

Imposto de renda. Aplicações financeiras pelas cooperativas. Lucros não sujeitos a tributos.

Não incide o imposto de renda sobre os lucros obtidos com aplicações financeiras feitas pelas cooperativas (Lei $n-5.764 / 71$ e Decreto $n$ 은 85.450/80) (STJ , 1998c).

Mas não só de vitórias para o cooperativismo se dão as decisões de nossos tribunais. Mesmo estando claro que o fato de que investimento em aplicações financeiras nada mais é do que uma forma da cooperativa se capitalizar para melhor realizar seus objetivos, e que o gerente que, ao invés de investir, optar por deixar pecúnia em caixa, sofrendo deterioração da inflação, ou não recebendo nenhuma remuneração, corre o risco de ser reconhecido incompetente no exercício de seu dever.

Imposto de renda. Cooperativa. Aplicação financeira. Incidência. 
Os lucros resultantes das aplicações financeiras, por não constituírem negócios vinculados à atividade básica das cooperativas, sujeitam-se à incidência do imposto de renda(STJ, 1997).

Operações financeiras. Cooperativas. Lei 5.764/71, art.111 (RIR/80, art. 129).

As operações financeiras das cooperativas decorrentes de sobras de caixa que produzem lucro estão suj eitas à tributação do Imposto de Renda. A isenção prevista na Lei n-5.764/71, em c/ c 0 art. 111, RIR/80, art.129, só alcança os negócios jurídicos diretamente vinculados à finalidade básica da associação cooperativa. Não são atos cooperativos, na essência, as aplicações financeiras em razão das sobras de caixa. A especulação financeira é fenômeno autônomo que não pode ser confundida com atos negociais específicos e com finalidade de fomentar transações comerciais em regime de solidariedade, como são os efetuados pelas cooperativas. A norma isencional não suporta interpretação extensiva, salvo situações excepcionais(ST], 1998b).

Mais uma vez, queremos reiterar que, em nosso pensamento, não se trata de capital especulativo a importância que as cooperativas porventura apliquem no mercado financeiro. Trata-se de capital da cooperativa referente a seus cooperados, que necessita ser bem gerido, visando ser reaplicado na mesma, possibilitando a consecução de seus objetivos.

\subsection{ICMS}

No âmbito tributário Estadual, nos ateremos a uma breve reflexão quanto ao Imposto Sobre Circulação de Mercadorias - ICMS, e sua controvertida incidência sobre atos cooperativos.

Segundo o que é dito pelo Direito Tributário, temos que a não incidência de imposto sobre 0 ato cooperativo cabe a partir do momento em que não há troca de titularidade, uma vez que os bens, como a produção dos cooperados, por exemplo, adentram a cooperativa para a consecução de seus obj etivos. Cooperativa esta que, ademais, pertence a seus cooperados, fato que, por conseguinte, suprime a transferência de propriedade. ${ }^{4}$

Nos pareceres citados abaixo, vemos que consenso não há, para nosso lamento, entre os Fiscos estaduais, no sentido de anuir com o acima exposto.

ICMS. Cooperativa. Ato tributável. Embargos a execução.

É tributável 0 ato cooperativo, assim entendido o alcance de matériaprima do associado para a cooperativa já que testifica circulação física, jurídica e econômica de bens. Compete a parte demonstrar a realização de operação com diferimento de imposto já que esta deve estar registrada em seus livros contábeis. Imposto informado em guia, desnecessidade de perícia, visto tratar-se de auto-lançamento. Essa informação não se compara com denúncia espontânea, multa devida pelo inadimplemento. Recurso improvido, argüição de nulidade rejeitada (SJ RS, 1999).

Tributário. ICM. Operação entre cooperativa e seus associados.

\footnotetext{
${ }^{4}$ Devemos ressaltar que esta linha de pensamento é defendida por vários pensadores do Direito Tributário, como Renato Lopes Becho e Roque Carrazza, os quais defendem os bens objeto do ato cooperativo como não sendo passíveis de se enquadrarem, a priori, na categoria de mercadorias, por não serem objeto de comércio.
} 
Não incidência de tributo, reconhecida por meio de sentença declaratória transita em julgado. Hipótese em que somente novo tratamento legal da matéria poderá ter 0 efeito de subtrair da eficácia da resjudicata as operações da espécie, realizadas elo contribuinte. Decidindo em sentido contrário, violou o acórdão a norma do art. 468 do CPC. Recurso provido (ST], 1990).

Tributário. ICM. Cooperativas. Decreto-lei n. 406/68.

É legítima a incidência do tributo nas operações por elas realizadas com seus associados. Precedentes do STF e desta Corte. Recurso improvido (ST) , 1991).

Apesar de alguns pareceres positivos, atentemo-nos para o último citado, o qual se baseia no Decreto-lei № 406/ 68 para alegar a tributação do ato cooperativo. Em seu §1으 do art. 6으, deixa explícito no inciso I que também são considerados contribuintes, para tal Decreto-lei, as cooperativas que, com habitualidade, pratiquem operações de circulação de mercadorias. Ora, tal dispositivo não acrescentou nada ao que já se entendia sobre tributação de atos não cooperativos, uma vez que cooperativas que praticassem tais atos habitualmente já se viam enquadradas a recolher ICMS. A interpretação dada pelos juristas ao Decreto-lei no 406/ 68 parece mostrar, a nosso ver, a extinção do ato cooperativo. De maneira alguma tal dispositivo possui força para tal.

\section{Impacto dos Tributos sobre uma Cooperativa}

A cooperativa na qual foi realizado este breve estudo encontra-se na região CentroNorte do Estado do Rio de Janeiro. Trata-se de uma cooperativa de receptação e beneficiamento de leite de seus cooperados.

A área de atuação da cooperativa compreende o município sede, bem como seus circunvizinhos. Tais cidades possuíam, segundo o Levantamento da Produção Pecuária Municipal de 2006, 3.545 estabelecimentos rurais produtores de leite, sendo que destes, cerca de 1630 enviavam sua produção para a cooperativa, uma participação de $46 \%$ Além do centro de recepção de leite e da indústria de beneficiamento no município sede, a cooperativa ainda conta com centros de receptação em outras duas cidades.

A cooperativa possui uma receita bruta da ordem de R\$38 milhões em 2006. Segundo dados da Organização das Cooperativas Brasileiras (OCB), neste mesmo ano, as 1.544 cooperativas agropecuárias representadas pela entidade foram responsáveis por $\mathrm{R} \$$ 34,2 bilhões em faturamento, ou seja, uma média de $\mathrm{R} \$ 22,2$ milhões por cooperativa. De acordo com Gimenes et al. (2003), algo em torno de 54\% das cooperativas agropecuárias singulares não ultrapassam os R \$ 40 milhões de faturamento anual.

0 volume de leite receptado em novembro de 2007 chegou a 2.226 .415 de litros/mês, provenientes em sua totalidade dos cooperados. Entretanto, deve-se destacar que a cooperativa possuía, na época, cerca de 3.400 associados matriculados, sendo que 1.710 destes estavam ativos, ou seja, entregaram a produção à cooperativa. Tendo em vista esses números, tem-se que, em média, cada produtor enviava algo em torno de 1.300 litros/mês, ou 43 litros/dia, o que faz-nos concluir que tais cooperados são, em sua maioria, pequenos produtores rurais, que têm na cooperativa alternativa viável, talvez a única, de interface com o mercado.

Baseando-se nos relatórios contábeis do ano de 2006, e restringindo a análise somente à atividade principal da cooperativa, os principais resultados obtidos indicam que as Obrigações Sociais, relacionadas aos seus 129 funcionários, representam 3,9\% do 
faturamento da cooperativa. Com relação ao IR, o valor chega a 1,4\% do faturamento total, incidente sobre os fretes e carretos feitos pela cooperativa na captação do leite, uma vez que a mesma não efetua compra de leite de não-associados. O ICMS pago pelo ramo agropecuário é reduzido, com o setor primário da economia respondendo por cerca de 1,29\% da arrecadação total deste tributo. Em 2006 a cooperativa pagou, relativo a este imposto, o corresponde a cerca de $4,5 \%$ do seu faturamento.

No total, algo em torno de $10 \%$ do faturamento bruto da cooperativa é gasto em tributos. Segundo o Diário do Comércio(DIÁRIO DO COMÉRCIO, 2008), o setor agropecuário da economia nacional tem tributação média de $14 \%$ sobre seu faturamento bruto.

A partir do exposto acima, conclui-se que, mesmo possuindo carga tributária inferior à média do setor agropecuário, o Estado pode atuar de forma a reduzir ainda mais o impacto dos tributos sobre as cooperativas, que se constituem, conforme já salientado, em importantes ferramentas de ligação entre produtores e o mercado. Tal redução seria ainda mais justificável se levarmos em consideração o grande número de pequenos e médios produtores associados a grande parte das cooperativas.

Nesse sentido, o exemplo apresentado abaixo vem demonstrar que o Estado pode, compreendendo a relevância do setor agropecuário, agir de modo a minimizar os impactos dos tributos no setor, assim como nas cooperativas integradas a ele.

\title{
4 O Estado do Rio de J aneiro e as Políticas de Fomento ao Setor
}

Desde 0 ano 2000, o Governo do Estado do Rio de J aneiro desenvolve o "Programa de Incentivo do Governo à Produção de Leite", que beneficia diretamente àqueles a quem o Estado realmente deveria beneficiar: os produtores rurais. Além disso, é destaque a ação implementada pelo Governo do Estado do Rio de Janeiro no intento de recuperar a Cooperativa Central dos Produtores de Leite - CCPL, utilizando-se, para isso, dos próprios tributos angariados pelos laticínios do Estado.

São ações em curso, ou já encerradas, postas em prática pelo Estado, que serão mais bem analisadas a seguir.

\subsection{Programa de Incentivo do Governo do Estado do Rio à Produção de Leite}

Instituído em 2000, com a publicação da Resolução Conj unta SEAAPI ${ }^{5}$ SEFCON $^{6}$ no 06 de 30 de março do referido ano, o "Incentivo do Governo do Estado à Produção de Leite" se articula de acordo com o que aclara seu art. 1ㅇ:

\begin{abstract}
Art. 1‥ Fica instituído o "Programa de Incentivo do Estado do Rio de J aneiro à Produção de Leite", mediante concessão de crédito presumido do ICMS aos contribuintes que adquirem leite produzido no Estado do Rio de Janeiro, diretamente do produtor ou através de usinas de laticínios legalmente estabelecidas no Estado do Rio de J aneiro, correspondente ao percentual de $12,28 \%$ (doze inteiro e vinte e oito décimos por cento),
\end{abstract}

\footnotetext{
${ }^{5}$ Secretaria de Estado de Agricultura, Abastecimento, Pesca e Desenvolvimento do Interior.

${ }^{6}$ Secretaria de Estado de Fazenda e Controle Geral.
} 
sobre o valor total dessas compras realizadas no período de abril de 2000 a 31 de março de 2001. (RIO DE J ANEIRO, 2000)

Para garantir a correta destinação dos benefícios, bem como buscar a sanidade do rebanho, como forma de contrapartida ao incentivo, atitudes pertinentes, a nosso ver, o art. 2ㅇ da Resolução Conj unta no 6 esclarece:

Art. 2․ 0 disposto no artigo anterior somente se aplica nos casos em que 0 valor do crédito presumido seja efetivamente repassado ao produtor, 0 que deverá ser feito junto ao pagamento relativo ao mês imediatamente posterior ao da apuração, sob o título: "INCENTIVO DO GOVERNO DO ESTADO"

Parágrafo único - 0 produtor, para fazer jus ao benefício, deverá:

I - estar inscrito no Cadastro de Contribuinte do ICMS - CAD - ICMS, e

II - comprovar, através de atestado fornecido pela Secretaria de Estado de Agricultura, Abastecimento, Pesca e Desenvolvimento do Interior, estar em dia com a vacinação do rebanho contra a febre aftosa.

Inicialmente, o crédito presumido somente se aplicava às compras realizadas entre 1 o de abril de 2000 a 31 de março 2001. Porém, duas resoluções sucessivas, a Resolução Conj unta SEAAPI/ SEFCON no 11 de 20 de abril de 2001 e a no 14 de 27 de agosto de 2001, prorrogaram a vigência da Resolução Conjunta SEAAPI/SEFCON nํ 06 de 30 de março de 2000 até 30 de junho de 2001, e 31 de dezembro de 2001, respectivamente. Tais postergações no termo final de vigência do programa já eram indícios de que o Estado percebeu a importância de tais incentivos. E com o Decreto no 29.042 de 27 de agosto de 2001, foram dados contornos definitivos ao que fora suscitado pela Resolução Conjunta SEAAPI/ SEFCON no 06 de 30 de março de 2000. Tal Decreto mantém as características da Resolução que o precede, como o item que beneficia diretamente as cooperativas, 0 art. 3:

Art. 3‥ As organizações às quais os produtores estejam integrados de forma associativa e direta e que a eles remuneram com valores percentuais iguais ou superiores a $50 \%$ (cinqüenta por cento) do valor médio de venda do leite ao varejista, incluindo-se nesta remuneração o valor correspondente ao incentivo de que trata 0 artigo 10 deste Decreto, podem se creditar do ICMS pela aplicação do percentual de 3,06\% (três inteiros e seis centésimos por cento), sobre o valor total das compras do leite realizadas a partir de 10 de janeiro de 2002, que serão destinados à "CONTA DE DESENVOLVIMENTO DA PECUÁRIA DE LEITE". (RIO DE J ANEIRO, 2001)

Os recursos previstos no artigo acima só poderiam ser utilizados caso a cooperativa elaborasse algum projeto que tivesse como objetivo o incremento à produção e/ou produtividade da atividade leiteira no Estado. Tal projeto deveria receber endosso técnico da EMATER - RIO e careceria ser aprovado pelo Conselho Municipal de Política Agrícola. Tudo isso a fim se afastar probabilidade de ação perdulária por parte das detentoras dos recursos.

Especificamente sobre o art. 30 do Decreto № 29.042 de 27 de agosto de 2001, foi publicada a Resolução Conjunta SEAAPI no 501 de 01 de agosto de 2001, a qual disciplina a elaboração de projetos do "Programa de Incentivo à Produção do Leite", como explana seu art. 10:

Art. 1‥ Os recursos contabilizados na conta especial denominada "CONTA DE DESENOLVIMENTO DA PECUÁRIA DE LEITE", na forma do disposto no §2. do artigo 3. $\cong$ do Decreto $\mathrm{n}$-29.042, de 27 de agosto de 20017, deverão ser

\footnotetext{
${ }^{7}$ Art. $30(\ldots)$

§2. - Os recursos previstos neste artigo serão contabilizados em Conta Especial denominada "CONTA DE DESENVOLVIMENTO DA PECUÁRIA DE LEITE" na contabilidade da organização beneficiária, e só poderão ser
} 
utilizados em projetos que objetivem o aumento da produção e da produtividade leiteira e que atendam as necessidades e os interesses coletivos dos produtores de leite, contemplando as seguintes ações:

I. nutrição e manejo reprodutivo;

II. melhoramento do padrão zootécnico;

III. educação sanitária;

IV. produção e armazenamento higiênico do leite;

V. diagnóstico, controle e/ou erradicação de doenças infecciosas, parasitárias, bem como ações e medidas profiláticas;

VI. controle de efluentes no âmbito das propriedades;

VII. reciclagem de técnicos;

VIII. profissionalização do produtor rural; e

IX. qualificação da mão de obra. (RIO DE J ANEIRO, 2001)

Não só o Incentivo do Governo do Estado à Produção de Leite, que favorece vários produtores do Estado do Rio de J aneiro, com acréscimo direto do benefício ao valor pago pelo litro do leite pela cooperativa ao cooperado, mas também o Programa de Desenvolvimento da Pecuária de Leite, que possibilitava às cooperativas provisionar recursos para ações em prol da produção leiteira, são exemplos concretos de como um tributo como o ICMS, tão controvertido, em termos de sua incidência ou não, entre as cooperativas, pode ter seu impacto diminuído de forma a fomentar, balizado por regulamentações do Estado, uma atividade fundamental a agropecuária fluminense.

\subsection{A Recuperação da CCPL - RJ}

A CCPL - Cooperativa Central dos Produtores de Leite foi criada em 1946 e tem uma história vitoriosa no estado. A cooperativa, instalada no município de São Gonçalo, Região Metropolitana, foi pioneira no país na fabricação de leite longa vida e iogurte e construiu uma marca forte na memória dos consumidores fluminenses.

Em meio à forte competição e mudanças no perfil do mercado, a CCPL interrompeu suas atividades em 2002, quando a dívida trabalhista, tributária, com fornecedores e com instituições financeiras acumulou $\mathrm{R} \$ 150$ milhões, comprometendo um grande número de pequenas cooperativas de produtores de leite que dependiam dela para vender a produção. Foi nesse contexto que se deu a publicação do Decreto no 38.233 de 14 de setembro de 2005, motivado não somente pela importância da CCPL, e da produção leiteira, para a economia do Estado, bem como pelo fato de muitos dos pequenos produtores de leite do Estado terem nesta atividade sua única fonte de renda.

0 Decreto tinha por finalidade principal o equacionamento do passivo financeiro da Central, fazendo uso de créditos de ICMS, conforme esclarece seu art. 10:

Art. 1‥ Os estabelecimentos industriais e produtores, integrantes da cadeia produtiva do leite, inclusive cooperativas e associações, localizados neste Estado poderão transferir os saldos credores escriturais acumulados do ICMS, para qualquer estabelecimento seu ou para outro contribuinte estabelecido no território fluminense, mediante pagamento em espécie, conforme 0 estabelecido no art. 30 deste decreto.

utilizados em projetos que objetivem o aumento da produção e da produtividade da atividade leiteira, devidamente endossados pela EMATER - RIO e aprovados pelo respectivo Conselho Municipal de Política Agrícola ou equivalente e encaminhados por relatórios específicos ao Conselho Estadual de Política Agrícola e Pesqueira - CEPAP/RJ ou ao Conselho Estadual de Desenvolvimento Rural Sustentável - CEDRUS, nos termos da Resolução a ser publicada pela secretaria de Estado da Agricultura, Abastecimento, Pesca e Desenvolvimento do Interior. 
Parágrafo Único - Os saldos credores acumulados a que se refere este artigo são os regularmente escriturados, devidamente reconhecidos como regulares e legítimos, pela Secretaria de Receita do Estado do Rio de J aneiro.

O que o Decreto permitia a partir de sua promulgação era nada mais do que a transação de créditos de ICMS entre integrantes da cadeia produtiva de leite e empresas de capital, ou não, mediante pagamento destes àquelas. Ao adquirente cabia o uso de tais créditos de forma a compensar débitos escriturais de ICMS, bem como para pagamento de crédito de ICMS, inscrito ou não na dívida ativa.

A transferência dos créditos de ICMS se dava como disposto no artigo 3o, explicitado abaixo:

Art. 3․ A transferência prevista neste Decreto poderá se dar nas seguintes alternativas, segundo opção prévia do detentor:

I - através de depósito, pelo adquirente, à conta PROGRAMA DE DESENVOLVIMENTO A PECUÁRIA LEITEIRA - PDPL, criada nos termos da ação civil pública 2005.004.024117-7 de 01 de junho de 2005, mantida junto ao Banco do Brasil, para o apoio à atividade produtiva do Estado do Rio de J aneiro, $70 \%$ (setenta por cento) do valor de compra do crédito escriturado até a data da publicação do presente decreto, a ser transferido, com direito do cedente/vendedor à restituição do valor recolhido, segundo condições a serem definidas pelo conselho de Administração Judicial da CCPL, no âmbito do Plano de Gestão, em conformidade com os termos da ação civil pública referida;

II - através de depósito, pelo adquirente, à conta PROGRAMA DE DESENVOLVIMENTO DA PECUÁRIA LEITEIRA - PDPL, criada nos termos da ação civil pública 2005.004.024117-7 de 01 de junho de 2005, mantida junto ao Banco do Brasil, para o apoio à atividade produtiva do Estado do Rio de J aneiro, 50\% (cinqüenta por cento) do valor de compra do crédito escriturado em qualquer data, a ser transferido, sem direito de restituição do cedente/ vendedor.

Deste modo, tanto se beneficiavam cedente e adquirente, mas também a CCPL, através da constituição de fundos para possibilitar sua alavancagem.

Desde a vitória na 4ạ Vara Cível da Fazenda de São Gonçalo - RJ, em junho de 2005, da Ação Civil Pública movida pela Procuradoria Geral do Estado no intuito de recuperar a CCPL, o Decreto № 38.233 de 14 de setembro de 2005 foi passo fulcral para que, em março de 2006, quatro anos após a interrupção de suas atividades, a Cooperativa Central dos Produtores de Leite - RJ fosse reativada.

Porém, com o Decreto produzindo efeitos até 31 de dezembro de 2006, a expiração do fundo criado pelo Estado levou a cooperativa a atravessar maus momentos no princípio de 2007. O apelo junto ao Governo, bem como um plano elaborado pelo seu Conselho de Administração J udicial, levaram o Estado a reativar o Fundo por meio do Decreto no 40.625 de 28 de fevereiro de 2007, nos moldes do já expirado Decreto № 38.233 de 14 de setembro de 2005.

Em seu art.1ํ, Parágrafo Único, o Decreto no 40.625 de 28 de fevereiro de 2007 dispõe:

Art. 1은

Parágrafo único - Os saldos credores acumulados a que se refere este artigo são os regularmente escriturados, devidamente reconhecidos como regulares e legítimos pela Secretaria de Estado de Fazenda do Rio de J aneiro, inclusive aqueles cuja transferência, solicitada nos termos do já expirado Decreto n. 0 38.233, de 14 de setembro de 2005, não tenha sido 
autorizada à época própria, mas já se encontrem devidamente homologados.

O acima citado denota visivelmente continuidade, bem como flexibilidade do Governo do Estado do Rio de J aneiro, a partir do momento em que possibilita utilização de saldos credores também de pedidos efetuados à época do antigo Decreto n. 038.233 , de 14 de setembro de 2005.

Com relação à formação do Fundo, objetivo principal do Decreto no 40.625 de 28 de fevereiro de 2007, 0 art. 20 esclarece:

Art. 2. - As autorizações para transferência de saldos credores acumulados do ICMS de que trata 0 artigo 1 o serão concedidas até perfazerem, em conjunto, o valor de $R \$ 15.000 .000,00$ (quinze milhões de reais).

Parágrafo único - O Secretário de Estado de Fazenda poderá autorizar as transferências dos saldos credores acumulados de que trata este artigo, atendendo à política econômica-tributária do Estado, observado 0 comportamento da receita e limitado aos seguintes percentuais, calculado cumulativamente, a serem aplicados sobre o valor mencionado no caput:

I - março de 2007: até 70\% (setenta por cento);

II - maio de 2007: até $93 \%$ (noventa e três por cento);

III - junho de 2007: até 100\%(cem por cento).

0 art. 2을 acima citado demonstra substancial acréscimo na expectativa do valor limite do Fundo, bem superior aos $\mathrm{R} \$ 4$ milhões angariados pelo Decreto precedente, 0 Decreto $n .038 .233$, de 14 de setembro de 2005. Além disso, diferentemente do anterior, o Decreto no 40.625 de 28 de fevereiro de 2007 não possui prazo limite para produzir efeito, estando o Fundo, de certo, subsidiando ações de seu Conselho de Administração J udicial, possivelmente, até que esta etapa de reestruturação da CCPL esteja concluída.

É válido destacar que não só o Governo do Estado do Rio de J aneiro buscou auxiliar financeiramente 0 Conselho de Administração da CCPL nestes dois últimos anos. Primeiramente, a ELEVA Alimentos S/A, em 21 de setembro de 2007, efetuou um empréstimo à CCPL no valor de R $\$ 2$ milhões, conjuntamente com uma proposta de estudo da estrutura de negócios da cooperativa, nos termos constantes em relatório enviado à Comissão de Valores Mobiliários, conforme abaixo:

Concorrência para Analisar a Estrutura do Negócio de Produtos Lácteos da CCPL

A Companhia apresentou proposta não vinculante para analisar a estrutura do negócio de produtos lácteos da Cooperativa Central de Produtores de Leite - CCPL.

(...) A proposta apresentada pela Companhia concorreu com outras propostas apresentadas aos Interventores Judiciais e foi considerada a vencedora em 18 de setembro de 2007.

Com a indicação de que a proposta apresentada pela Companhia foi a vencedora, as partes iniciaram negociações de Termo de Intenção não vinculante, ou documento similar, para início de estudos, realização de diligência legal, contábil e operacional, e negociação de alternativas de investimento pela Companhia na CCPL através de aquisição, celebração de contratos comerciais entre as partes, ou qualquer outra estrutura a ser acordada de comum acordo entre as partes.

Em 21 de setembro de 2007, as partes celebraram Memorando de Entendimentos não vinculante e Contrato de Empréstimo pelo qual foi disponibilizado pela Companhia à CCPL linha de crédito no valor de R\$ 2 milhões, com juros equivalentes a $12 \%$ (doze por cento) ao ano, calculado sobre o valor total do crédito, atualizado anualmente de acordo com a variação do IGP-M e vencimento em até 180 (cento e oitenta) dias. Em 09 de outubro de 2007 foi celebrado com a CCPL contrato de industrialização 
e fornecimento de produtos lácteos por período de 03 (três) meses, renováveis por igual período, à opção da Companhia(CVM, 2007).

Tal relatório parece deixar claro o intuito da ELEVA junto à CCPL. A intenção de compra parece ser uma realidade confirmada em março de 2008 , quando a PERDIGẪO S/ A realizou novo investimento de $R \$ 3$ milhões na ampliação da capacidade de beneficiamento da cooperativa, segundo informação do Diário Catarinense ${ }^{8}$. A PERDIGÃO adquiriu a ELEVA um mês após a realização do empréstimo concedido por esta à CCPL. A manutenção da posição frente à cooperativa dá a entender que a CCPL continua nos planos de aquisição, agora, da PERDIGÃO, logo termine o processo de reestruturação da cooperativa.

\section{Considerações Finais}

Diante de pareceres equivocados, de incidência de tributos sobre atos cooperativos, de injustiças cometidas e de desconsiderações acerca das benesses do cooperativismo, vemo-nos desamparados em nossa defesa do sistema cooperativista. Porém, mesmo quando - Estado demonstra estar despreparado para lidar com tal sistema e quando a tendência parece ser igualar cooperativas a qualquer outra forma de organização produtiva, surge, mesmo que de maneira tímida, algumas ações pontuais, como as praticadas pelo Estado do Rio de J aneiro.

Acerca de ações levadas a cabo pelo Governo do Estado, mais especificamente o "Programa de Incentivo do Governo à Produção de Leite", constatamos que, apesar de contemplarem mais um setor de atividade pecuária do que o cooperativismo propriamente dito. Trata-se de passo importante e decerto marcante às cooperativas do setor, uma vez que o tão controvertido ICMS encontra desígnios, se não aqueles esperados, pelo menos mais racionais e proveitosos, em acordo com a finalidade do Estado em apoiar pequenos produtores em uma atividade de vital importância. E na pecuária leiteira fluminense, as cooperativas são o baluarte principalmente dos pequenos e médios produtores, e a CCPL, junto com suas singulares, não poderiam simplesmente desaparecer. Neste sentido se justifica a preocupação do Governo do Estado do Rio de Janeiro diante do encerramento das atividades da cooperativa.

Numa análise estrita acerca destes fatos, percebemos que estávamos lidando com o fenecimento iminente de mais uma cooperativa, sucumbindo ante empresas de capital. Porém, o aprofundamento desta questão aqui não nos cabe. Somente sinalizamos para o fato de que a continuidade do auxílio do Governo do Estado, mesmo com esta evidente ação de compra da CCPL pela PERDIGÃO S/A, se justificaria na medida em que, cooperativa ou não, a CCPL continua sendo uma usina de laticínios legalmente estabelecida no Rio de Janeiro, cumprindo seu papel de empregadora direta e indireta, dentre outras considerações, utilizadas tanto no Decreto no 40.625 de 28 de fevereiro de 2007, quanto no já expirado Decreto no 38.233 de 14 de setembro de 2005.

Não queremos aqui exigir o fim do auxílio do Governo do Estado do Rio de J aneiro a quaisquer usinas de laticínios que não se constituam na forma de cooperativa. Entretanto, apesar de exaltarmos a ciência do Governo fluminense quanto à importância do cooperativismo no Estado, confessamos não ser este o fim que esperávamos à ação de intervenção judicial da CCPL, na qual depositávamos esperanças do ressurgimento de uma cooperativa mais forte.

${ }^{8}$ Perdigão investe R\$ 3 milhões na CCPL. Diário Catarinense, Florianópolis, 07 de março de 2008, № 7998. 


\section{Referências}

ANDRIGHI, Fátima Nancy. A Autonomia do Direito Cooperativo. In: KRUEGER, Guilherme (Coord.). Cooperativismo e o Novo Código Civil . Belo Horizonte: Mandamentos, 2003

BECHO, Renato Lopes. Elementos de Direito Cooperativo. São Paulo: Dialética, 2002.

Tributação das Cooperativas. 3.ed. São Paulo: Dialética, 2005.

BRASIL. Constituição da República Federativa do Brasil de 1988. 31. ed. São Paulo: Saraiva, 2003

Código Tributário Nacional. Lei 5.172/66. 25. ed. São Paulo: Saraiva, 1996.

Lei no 5.764, de 16 de dez. de 1971. Diário Oficial (da República Federativa do Brasil), Brasília, DF, 16 de dez. 1971.

CARRAZZA, Roque Antônio. ICMS. 2. ed. São Paulo: Malheiros, 1995.

INSTITUTO BRASILEIRO DE GEOGRAFIA E ESTATÍSTICA. Produção Pecuária Municipal 2006. Rio de J aneiro, v. 34. p. 1- 64. 2006.

PEAKE, Ricardo. Sociedades Cooperativas no Novo Código Civil. In: PEAKE, Ricardo (Coord.). Coope

PRADO, Flávio Augusto Dumont. Tributação das Cooperativas à Luz do Direito Cooperativo. Curitiba: J uruá, 2007.

RIO DE J ANEIRO. Resolução SEFAZ no 21, de 07 de março de 2007. Diário Oficial (do Estado do Rio de J aneiro), Poder Executivo, Rio de J aneiro, RJ , 08 de mar. 2007a.

. Decreto № 40.625, de 28 de fevereiro de 2007. Diário Oficial (do Estado do Rio de

J aneiro), Poder Executivo, Rio de J aneiro, RJ , 01 de mar. 2007b.

Decreto no 38.233, de 14 de setembro de 2005. Diário Oficial (do Estado do Rio de J aneiro), Poder Executivo, Rio de J aneiro, RJ , 15 de set. 2005.

Resolução Conjunta SEAAPI no 501, de 01 de agosto de 2001. Diário Oficial (do Estado do Rio de J aneiro), Poder Executivo, Rio de J aneiro, RJ , 11 de dez. 2001a.

Decreto no 29.042, de 27 de agosto de 2001. Diário Oficial (do Estado do Rio de Janeiro), Poder Executivo, Rio de J aneiro, RJ , 29 de ago. 2001b.

. Resolução Conjunta SEAAPI/ SEF no 14, de 27 de agosto de 2001. Diário Oficial (do Estado do Rio de J aneiro), Poder Executivo, Rio de J aneiro, RJ , 28 de ago. 2001c.

Resolução Conjunta SEAAPI/ SEFCON no 11, de 20 de abril de 2001. Diário Oficial

(do Estado do Rio de J aneiro), Poder Executivo, Rio de J aneiro, RJ , 25 de abr. 2001d.

Resolução Conjunta SEAAPI/ SEFCON № 06, de 30 de março de 2000. Diário Oficial (do Estado do Rio de J aneiro), Poder Executivo, Rio de J aneiro, RJ , 03 de abr. 2000.

SOUSA, Rubens Gomes. Compêndio de legislação tributária. São Paulo: Resenha Tributária, 1975.

VASCONSELOS, Francisco das Chagas (Org.). Cooperativas: coletânea de doutrina, legislação, jurisprudência e prática. São Paulo: Iglu, 2001.

\section{ENDEREÇO DOS AUTORES}

Universidade Federal de Viçosa

Campus Universitário

Viçosa, MG - Brasil

36570-000 